\title{
The Integrated Model of Dwyer and Kim as a Tool to Evaluate and Rank the Determinant Attributes of a Tourist Destination Competitiveness
}

\author{
Sonila Berdo \\ University Pavaresia Vlore, Albania. \\ sonila. berdo@unipavaresia.edu. al or soniberdo@yahoo. it
}

\begin{abstract}
The aim of this paper is to explain the importance of the Integrated model of Dwyer \& Kim, in terms of its application to different tourist destinations, as a valuable tool to measure and evaluate the impact of different factors in their competiveness level and making possible to compare them to each other. Managing tourist destination competitiveness is a very challenging process. This model serves as a tool to identify, to evaluate and rank the importance of different attributes and sub-attributes of a tourist destination. Having the information on the relative importance of all the factors and sub-factors makes destinations/countries well oriented to select and invest or effectively manage those factors which are of high impact in achieving and maintaining the sustainable competitiveness level in the market. How this model is composed? Which factors and sub-factors are involved in this model for being evaluated and ranked, as tourist destination competitiveness attributes? How these factors and subfactors can be converted in measurable ones? How this model can be applied in practice? Answering the above questions and giving some evidences in different countries about the last question will be the objectives of this paper. After a literature review process on different models of evaluating tourist destination competitiveness, the integrated model of Dwyer \& Kim, here presented, results as the most completed model which does integrate the both sides of the tourist market factors, those of the supply and demand side.
\end{abstract}

Keywords: tourist destination competitiveness, Dwyer \& Kim model, tourist factors ranking.

\section{Introduction}

Nowadays, tourist destinations are operating in terms of the international market. They are involved into the accelerated process of globalization, under the conditions of economic, social and technological changes and that of a dynamic market. Consequently, competition between destinations is growing and is becoming increasingly difficult to be managed. In order that a destination becomes and remains successful in the market, it must be able to offer a unique experience to the tourists, which is produced by the combination of attributes of that destination.

In a context like this, the tourist destination competitiveness needs to be analysed and strategically managed, even though this is associated with a variety of problems and challenges such as the impacts of factors and unpredictable events; a part of attributes are difficult to be managed; in managing elements of an attribute, a large number of organizations do affect; tourism development is associated with costs and benefits and there is no consensus on the social, economic and environmental impacts that may have; destinations do not establish clear development targets on which to assess the competitiveness of their performances; it suffers by lack of objective information, measures and indicators; given that competitiveness is a relative concept, the competitiveness of a destination is a function of what happens at the destination.

Even though tourist destination competitiveness affords so many problems and challenges like above mentioned, many authors have contributed with their researches in conceptualising and creating competitiveness models that help and facilitate the process of identifying, analysing, measuring and evaluating the competitiveness level of a tourist destination, explaining the competitive advantages resources and trying to lead to the right path the destination competitiveness management in a sustainable way. Here, it can be mentioned different models like: Tourist area life cycle model (Butler, 1980); National Diamond of Porter (Porter, 1990), Crouch and Ritchie model (2000); and the model which this paper is dedicated to, that of Integrated model of Dwyer and Kim (2003).

Each of the tourist destination models according to the theoretical analyses and empirical evidences offered by tourist literature shows its own advantages and disadvantages, depending on the study context where they are used. 


\section{Integrated Model of Destination Competitiveness of Dwyer \& Kim}

One of the last trends in the tourism research field is that of analysing the relative importance of the destination competitiveness attributes, in order to manage effectively the limited resources of a destination. The models which makes possible to identify, to measure, to evaluate and rank the attributes and determinant factors of a tourist destination and to compare different tourist destinations with each other related to their specific attributes, there are especially two of them: Crouch and Ritchie model and Integrated model of Dwyer \& Kim.

These two models are of general nature and as such can be implemented to any tourist destination.

Compared to Crouch and Ritchie model, that of Dwyer and Kim besides taking in consideration factors such as the destination policy, planning and development, destination management, core resources and attractive factors, and supportive resources which constitute the tourist supply side, do include also factors of tourist demand side. But, how is composed this model? Which are the categories of attributes and sub-attributes, included in this model? How can they be converted in identifiable variables? How can this model be put in practice? These questions and some cases where this model has been applied will be explained in the following part of this article.

\section{Integrated Model of Dwyer and Kim Composition}

According to Dwyer \& Kim model, the tourist destination competitiveness is conceptualized as a function of six categories of attributes, which are as follows: Inherited resources, created resources, supporting resources, destination management, demand factors and situational factors. Each of the attributes' categories does include sub-attributes which in total summarize 85 elements, structured as a decision making tree. Below, it is described briefly each of the attributes' categories and also in each case are given the variables that helps in identifying and evaluating the different sub-attributes and their respective attributes of the tourist destination.

Inherited resources - It is the attribute that measures the attractive power of a destination by describing the basic elements of its attractiveness. Components of this attribute do constitute the basic reasons why tourists choose a destination vs. another. They do represent historical sites, heritage, traditional art, flora and fauna, artistic and architectural features, the nature, natural parks, the climate.

Created resources - This attribute category provides the basis of creating a successful tourism. These are additional elements of inherited resources which have an important role in improving the position of the destination. The key variables or sub-attributes included in this category are as follows: nightlife, special events/festivals, food service facilities, resorts/spa-s, winter activities, diversity of "shopping" experience, rural tourism, recreation, natural based activities, conference tourism, community support, sports facilities, transport efficiency, casinos, adventure activities, accommodation, facilities for recreation, tourism guides and information, quality and efficiency of airport, entertainment parks, visitor access to natural environments, water-based activities.

Supporting factors and resources - residents' hospitality, exchange facilities and financial institutions, telecommunication system, the behaviour of customs and immigration officials, the quality of the tourism sector, communication and confidence relations between residents and visitors, health service facilities for tourists, access to the destination, the destination ties with markets of origin, the visa requirements.

Destination management - Group of factors that focuses on managing effectively the inherited and created resources, and supporting factors to increase their attractive abilities toward the tourists. This group of factors contributes at the same time to increase the attraction, the quality and effectiveness of all the other factors, thus creating the most direct mechanism for managing the destination's competitiveness and sustainability. Sub- factors under this category are as follows: the importance of services quality, clear policies of destination toward social tourism, destination vision reflecting residents, visitors and interest groups values; developing effective destination brands; education structure of tourism sector employees; tourist firms efficiency; quality of local tourist entrepreneurships; availability of proper education programs on tourism field; increase of FDI in tourism sector; government cooperation in tourism policies development; commitment of private sectors to the education in tourism field. 
Demand conditions - includes three elements of tourism demand which are: the information, the perceptions and preferences of the tourists. They can be found under variables like: the compatibility level of the product features with the tourist preferences; international awareness of destination products; general image of the destination; international awareness of the destination.

Situational factors represent the situational factors which may moderate or smooth the destination competitiveness. Among these factors may be mentioned location, micro and macro environment, safety, price competition. Variables which can indicate this category of factors may be as follows: the collaboration between private and public sectors; environmental investments; managers' abilities; politic stability; visitors security; e-commerce usage; information technology usage by companies.

\section{About Model Application}

The instrument which makes possible the application of Dwyer and Kim model in practise is the questionnaire, which must be composed by taking in consideration the wide inclusion of six factors categories and their 85 sub-factors, by synthetizing and adapting them to different objectives, nature and context of a research study.

In order to gather data on the relative importance of attributes the questionnaire must be addressed to the groups of experts and not to the tourist themselves since they cannot evaluate more than what they consume in a tourist destination and not what entirely offers.

In general there are two groups of experts to whom the questionnaire is addressed. First group is that of managers of destination management organisations like: national tourism administration, public and private tourist offices, and regional tourist organisations. While, the second group of experts are that of researchers and scientists of destination management and marketing field.

Experts will judge and evaluate on the importance of each attribute and sub-attribute of the questionnaire, according to a given points scale chosen. The data gathered after completing the questionnaires, will be processed by different statistical and ranking technics. The information obtained finally will show the relative importance of the attributes and sub-attributes of a destination or destinations under comparison process (if the aim of the research is that. )

\section{Some Cases of Dwyer and Kim Model Application}

Vodeb (2010), analyzed the tourist destination competitiveness of 7 cross border areas between Croatia and Slovenia, by using the extended model of Crouch and Ritchie. His research focused on tourism supply providers in the border regions of Slovenia and Croatia aiming to assess their attitudes on tourism, regional competitiveness, and potential tourism destinations as the outcome of cooperation between the two countries, by offering integrated tourist products. To analyze the providers' attitudes, a questionnaire of 41 questions and sub-questions and 65 variables was addressed to a group of experts. The experts had to evaluate the tourism quality according to a ranking system of five scale points, from 1 to 5 . The method used to analyze the fact that if the cooperation between the two countries would increase the destinations competitiveness was that of factorial analyses.

Armenski Tanja, Marković Vladimir (2011), analysed Serbian destination competitiveness as a tourist destination in comparison with its main competitors. The aim of this research was to determine the weakest and strongest points of Serbian destination, in order to improve those conditions which would be the resources of future and sustainable competitive advantages of this destination. The destination competitiveness in this case was analyzed and evaluated through the integrated model of Dwyer and Kim, by taking in consideration the tourist demand side and supply side factors. The researchers used the experts' judges of tourism field to evaluate and rank the importance of Serbia destination competitiveness factors. After that, the data obtained were processed by Paired Sample Test, in order to have the relative importance ranking of all the attributes and sub-attributes. , which shows how the factors stands in front of each other and on the other hand the main competitors stands in front of Serbia related to each competitiveness factor. The results showed that Serbia is more competitive in its natural, cultural and created resources than in destination management while, 
according to the Integrated model, Serbia is less competitive in demand conditions that refer to the image and awareness of the destination itself.

\section{Conclusions}

The integrated model of Dwyer and Kim, do offer the necessary structure to evaluate the destination competitiveness by fulfilling the criteria of sustainability and long term effects towards the standard of living and life quality of the residents.

This model offers the most complete structure to be used in comparing destinations and evaluating relative importance of different attributes since it includes all the factors of the demand and supply side of tourism products of a destination. The way the attributes are categorized is very useful and significant for further analyses and evaluations of destination competitiveness perspectives.

However, this models has some of its limits as follows: 1) There can be more than 85 sub-attributes to a destination and their aggregation within 6 categories of attributes becomes difficult; 2) Many of the attributes are measured in a qualitative manner, multi-dimensional, abstract and inaccurate way; 3) Finding data for each attribute is difficult, since some of the data either do not exist or are unreliable; 4) Measurement of the dependent variable as the destination competitiveness is also problematic.

\section{REFERENCES}

[1] Goffi, Gianluca - Tourism destination competitiveness: theoretical models and empirical evidence. Università Politecnica delle Marche, Doctoral Thesis, 2011/2012.

[2] T. Armenski, D. Gomezelj, B. Djurdjev, N. Ć, and A. D (2012). Tourism destination competitiveness - between two flags. Economic Research - Ekonomska istraživanja, Vol. 25 (2012) No. 2 (485-502).

[3] Dwyer, Larry and Kim, Chulwon. (2003). Destination competitiveness: A Model and Determinants. Current Issues in Tourism 6, 369-414.

A. Tanja, M. Vladimir, D. N and A, J. Tamara (2011). A Integrated Model of Destination Competitiveness. Geographica Pannonica, Volume 15, Issue 2, 58-69.

[4] Vodeb, Ksenija, Cross-Border Regions as Potential Tourist Destinations Along the Slovene Croatian Frontier (November 5, 2010). Tourism \& Hospitality Management, Vol. 16, No. 2, 2010.

[5] HASSAN, S. S. , 2000. Determinants of market competitiveness in an environmentally sustainable tourism industry. Journal of Travel Research, 38 (3), pp. 239-245. 